Rev. Saúde públ., S. Paulo, 19:401-10, 1985.

\title{
PRODUTOS DE PESCA E CONTAMINANTES QULMICOS NA ÁGUA DA REPRESA BILLINGS, SÃO PAULO (BRASIL)
}

\author{
Aristides Almeida Rocha* \\ Denise Navas Pereira** \\ Helcias Bernardo de Pádua**
}

\begin{abstract}
ROCHA, A.A. et al. Produtos de pesca e contaminantes químicos na água da Represa Billings, São Paulo (Brasil), Rev. Saúde públ., S. Paulo, 19:401-10, 1985.

RESUMO: Através da análise dos surfactantes determinados pelo método colorimétrico com azul de metileno, e dos metais pesados determinados por espectrofotometria de absorção atômica, como o cádmio, chumbo, cobre, cromo, mercúrio e zinco, foi caracterizada a poluição na Represa Billings, SP (Brasil), enfatizando a qualidade sanitária da água e a contaminação dos peixes. Com base nos dados coligidos, é mostrado o perigo potencial que representa o consumo do pescado proveniente da Billings, se bem que a pesca comercial esteja hoje praticamente restrita às cabeceiras dos braços dos rios Capivari e Pequeno, na junção próxima a Ribeirão Pires e nos braços dos rios Curucutu e Taquacetuba. Os dados da CEAGESP - Companhia de Entreposto de Armazéns Gerais do Estado de São Paulo — indicam que, no ano de 1980, apenas 64 toneladas de peixe provieram de São Bernardo do Campo.
\end{abstract}

UNITERMOS: Água, poluição (produtos químicos). Peixes, contaminação.

\section{INTRODUÇÃO}

Em 1947, o inglês Turing ${ }^{18}$ declarava: "Os peixes constituem um barômetro muito útil do real estado de pureza de uma água. Nenhum corpo d'água pode ser considerado em condições satisfatórias se nele não viverem e proliferarem peixes".

Nesse caso, a Represa Billings, no Estado de São Paulo, próxima à Serra do Mar, a $23^{\circ} 42^{\prime}$ Lat. Sul e $46^{\circ} 42^{\prime}$ Long. $\mathrm{W}$, constitui um triste exemplo negativo, pois a maioria das espécies da ictiofauna ainda existentes apenas conseguem sobreviver por possuírem adaptações que lhes confere resistência ou, por ocorrer, em certos períodos, a reposição de peixes efetuada pelo homem para manutenção dos cardumes.

Quanto ao comportamento dos peixes, frente a um ambiente tão adverso, pen- sando de maneira antropomórfica, segundo Branco ${ }^{5}$ (1972), poder-se-ia ter a impressão de que esses animais, em intensa atividade, procurassem afastar-se imediatamente quando da presença de um tóxico. Contudo, a exemplo do homem, caso há em que eles são incapazes de perceber ou de reagir sob ação de um elemento nocivo qualquer $\mathrm{e}$, às vezes, em estado letárgico, não empreendem a fuga.

Todas essas situações devem ocorrer em um meio aquático tão desequilibrado como a Represa Billings, concorrendo para a redução cada vez maior da ictiofauna. Pafundi ${ }^{16}$ (1976), assinala a sensível queda no número de pescadores que trabalhavam na Represa.

Embora, como ressalta Bonetto ${ }^{4}(1980)$, os represamentos possam trazer série de problemas à produção pesqueira, precisa

\footnotetext{
- Do Departamento de Saúde Ambiental da Faculdade de Saúde Pública da Universidade de São Paulo - Av. Dr. Arnaldo, 715 - 01255 - Săo Paulo, SP - Brasil. Da Escola de Engenharia Maú́ - Estrada das Lágrimas, 2035 - 09500 - São Caetano do Sul, SP - Brasil. Da Companhia de Tecnologia de Saneamento Ambiental - CETESB - Av. Prof. Frederico Herman Júnior, $345-$ 05459 - São Paulo, SP - Brasil.

* Da Companhia de Tecnologia de Saneamento Ambiental - CETESB.
} 
ROCHA, A.A. et al. Produtos de pesca e contaminantes químicos na água da Represa Billings. São Paulo (Brasil). Rev. Saúde públ., S. Paulo, 19:401-10, 1985.

ser ressaltado que, no caso da Represa Billings, antes de haver o represamento, o rio Grande e seus principais afluentes não eram rios que apresentassem uma piscosidade que pudesse suportar uma pesca em escala comercial. Com o advento da Represa, 1937, e a posterior colocação de peixes, iniciada a partir de 1948, pelo antigo Serviço de Piscicultura da Ligth (Mendes-Sobrinho ${ }^{13}, 1969$ ), começou a pesca sistematizada, chegando a Represa, vinte anos mais tarde, a contribuir com 215,7 toneladas do pescado, que entraram na Companhia Entreposto de Armazéns Gerais do Estado de São Paulo - CEAGESP, antigo CEASA.

Nos anos 60, a atividade de pesca nos 13.000 ha. da Represa, através dos postos-colonias de Riacho Grande, São Bernardo do Campo e Paranapiacaba, era bastante intensa.

A colocação de peixes na represa Billings foi feita primeiramente com carpas (Cyprinus carpio) e, posteriormente, com a tilápia importada do ex-Congo Belga (Zaire), em 1953.

A Tilapia rendalli ( $T$. melanopleura) viria a dominar completamente a Represa Billings, assenhoreando-se do nicho ecológico, desalojando e diminuindo a população de outras espécies de peixes na Represa.

Charlier $^{8,9}(1955,1957)$ relata que as criações eram efetuadas na Estação Central de Piscicultura de Varginha (SP) (Criadouro de Varginha), na Via Anchieta e nas subsidiárias: Criadouro da Pedreira, Criadouro do Caminho do Mar e Criadouro do Rio das Pedras.

Infelizmente, no início da década de 70 , essa atividade foi interrompida, havendo a desativação de uma das estações de piscicultura e as duas outras passando a produzir abaixo da real capacidade, apenas para atendimento a particulares. Assim, a produção, que chegou a atin- gir uma, tonelada diária de pescado na Billings, foi sensivelmente diminuída.

Embora, pela classificação de Machado e col. ${ }^{12}$ (1968) - que agrupa o pescado de água doce nas categorias, "fino", "primeira" e "popular" — os peixes da Billings possam, na grande maioria, ser classificados apenas na última categoria, quais sejam, a tilápia (Tilapia rendalli), bagre (Rhamdia sp), traíra (Hoplias malabaricus), lambari (Astyanax bimaculatus), saguiru (Curimatus $s p$ ), carpa ( $C y$ prinus carpio) e o acará (Geophagus sp)*.

A pesca comercial, que chegou à produção total média de 20 toneladas diárias, acabou por ser praticada em pequena escala, reduzindo-se sensivelmente durante 0 inverno, pois os peixes de maior significado econômico migram para o fundo, dificultando a sua captura. As redes de pesca pouco podem ser usadas pois, em profundidade, a soqueira e galhos que permaneceram submersos após o enchimento e devido à oscilação do nível da Represa em função da operação ile recalque causam inúmeros problemas com a danificação e até perda do material, além de provocar seletividade na captura.

O presente trabalho procura evidenciar as concentrações de poluentes consideradas críticas para o pescado, destinado a alimentação.

\section{OS SURFACTANTES E OS PEIXES}

Foram efetuadas análises nos laboratórios da Companhia de Tecnologia de Saneamento Ambiental (CETESB) e no Laboratório de Hidrobiologia e Físico-Química do Departamento de Saúde Am-

\footnotetext{
* Relatos de antigos pescadores indicam que havia ali abundância de espécies de maior valor comercial, como o mandi (Pimelodus sp), tubarana (Salminus hilarii) e a piava (Leoporinus sp). Presentemente, a própria carpa passou a ser raramente encontrada, estando também praticamente extinto o cascudo (Plecostomus sp).
} 
ROCHA, A.A. et al, Produtos de pesca e contaminantes químicos na água da Represa Billings, São Paulo (Brasil). Rev. Saúde públ., S. Paulo, 19:401-10, 1985.

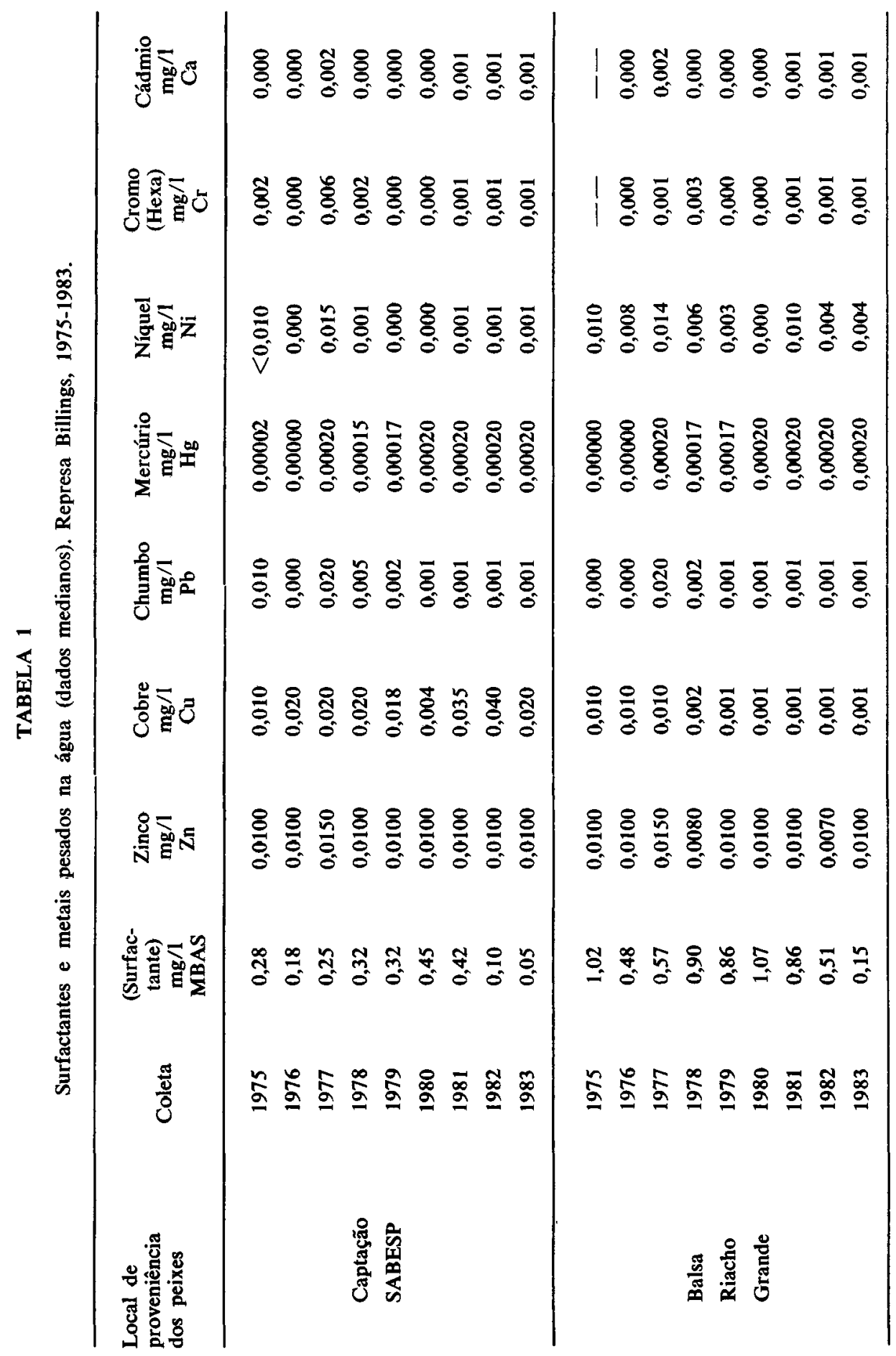


ROCHA, A.A. et al. Produtos de pesca e contaminantes químicos na água da Represa Billings. São Paulo (Brasil). Rev. Saúde públ., S. Paulo, 19:401-10, 1985.

biental da Faculdade de Saúde Pública da Universidade de São Paulo - USP, utilizando o método colorimétrico, com azul de metileno, descrito no "Standard Methods for the Examination of Water and Wastewater" (1980). Verificou-se que desde 1975 (Tabela 1) apenas nos anos de 1976, 1982 e 1983, junto à captação de água para as cidades de Santo André, São Caetano do Sul e São Bernardo do Campo e em 1983, junto à Balsa do Riacho Grande, o limite para surfactantes permaneceu abaixo do máximo permissível. Nos demais anos, conforme a Tabela 1 , nas duas zonas consideradas, o limite de $0,2 \mathrm{mg} / 1$, estabelecido pela "Environmental Protection Agency" (EPA), em 1972, foi sempre ultrapassado.

Os surfactantes conferem gosto atípico à carne de peixes, reduzindo seu valor comercial. Além disso, as espumas podem albergar bactérias e fungos patogênicos e metais pesados.

Castro e col..$^{7}$ (1979), trabalhando com espumas da Represa Billings na região do "Summit Control", verificaram a presença dos metais pesados, relacionados na Tabela 2.

TABELA 2

Metais pesados na espuma (dados médios). Represa Billings

\begin{tabular}{llc}
\hline Metal & $\begin{array}{c}\text { Água } \\
\mathrm{mg} / 1\end{array}$ & $\begin{array}{r}\text { Espuma } \\
\mathrm{mg} / \mathrm{kg}\end{array}$ \\
\hline Cádmio & 0,01 & 3,3 \\
Chumbo & 0,04 & 16,8 \\
Cobre & 0,005 & 1335 \\
Mercúrio & 0,00017 & $\mathbf{1 , 8 3}$ \\
\hline
\end{tabular}

Fonte: Castro e col.' (1979)

Portanto, há sério comprometimento na Billings, principalmente em relação ao pescado, pois os dados medianos da Tabela 1 mostram que, durante vários anos, a água apresentou valores superiores a $1,0 \mathrm{mg} / \mathrm{l}$, com a formação de extensas "massas" espumantes.
Embora os surfactantes, física e quimicamente apresentem muitas diferenças entre sí, possuem a propriedade comum de baixar a tensão superficial dos líquidos, nos quais estão dissolvidos, podendo causar eutrofização e apresentar toxicidade variável.

Abel $^{1}$ (1974) cita essas substâncias orgânicas como agentes de toxicidade aguda a peixes, quando em concentrações de 0,4 a $40 \mathrm{mg} / \mathrm{l}$, tendo como fatores de influência no toxicante a estrutura molecular da substância, a dureza, a temperatura e a concentração de oxigênio dissolvido na água, além da idade e espécie de peixe considerado.

Concentrações de $0,1 \mathrm{mg} / 1$ de surfactantes podem interferir no desenvolvimento de estágios juvenis de alguns invertebrados e, também, propiciar efeitos sinérgicos, aumentando a incorporação de outros poluentes.

\section{OS METAIS PESADOS E OS PEIXES}

Os metais pesados, denominação genérica de uma série de elementos que ocupam as colunas centrais da classificação periódica, podem ter propriedades tóxicas, tanto no estado elementar como quando combinados.

As concentrações de metais pesados na Represa foram efetuadas através de determinações em espectro fotômetro de absorção atômica, de acordo com o "Standard Methods for the Examination of Water and Wastewater"', 1980, nos laboratórios da Companhia de Tecnologia de Saneamento Ambiental (CETESB). As Tabelas 1 e 3 indicam que, em grande parte, essas .concentrações ultrapassam os limites máximos permissíveis para a manutenção da fauna aquática, principalmente peixes. Padua e col. ${ }^{15}$ (1983) apresentam trabalho inserindo série de dados e, entre eles, são discriminados os limites máximos para água doce, quanto à preservação da vida dos pei- 
ROCHA, A.A. et al. Produtos de pesca e contaminantes químicos na água da Represa Billings. São Paulo (Brasil). Rev. Saúde públ., S. Paulo, 19:401-10, 1985.

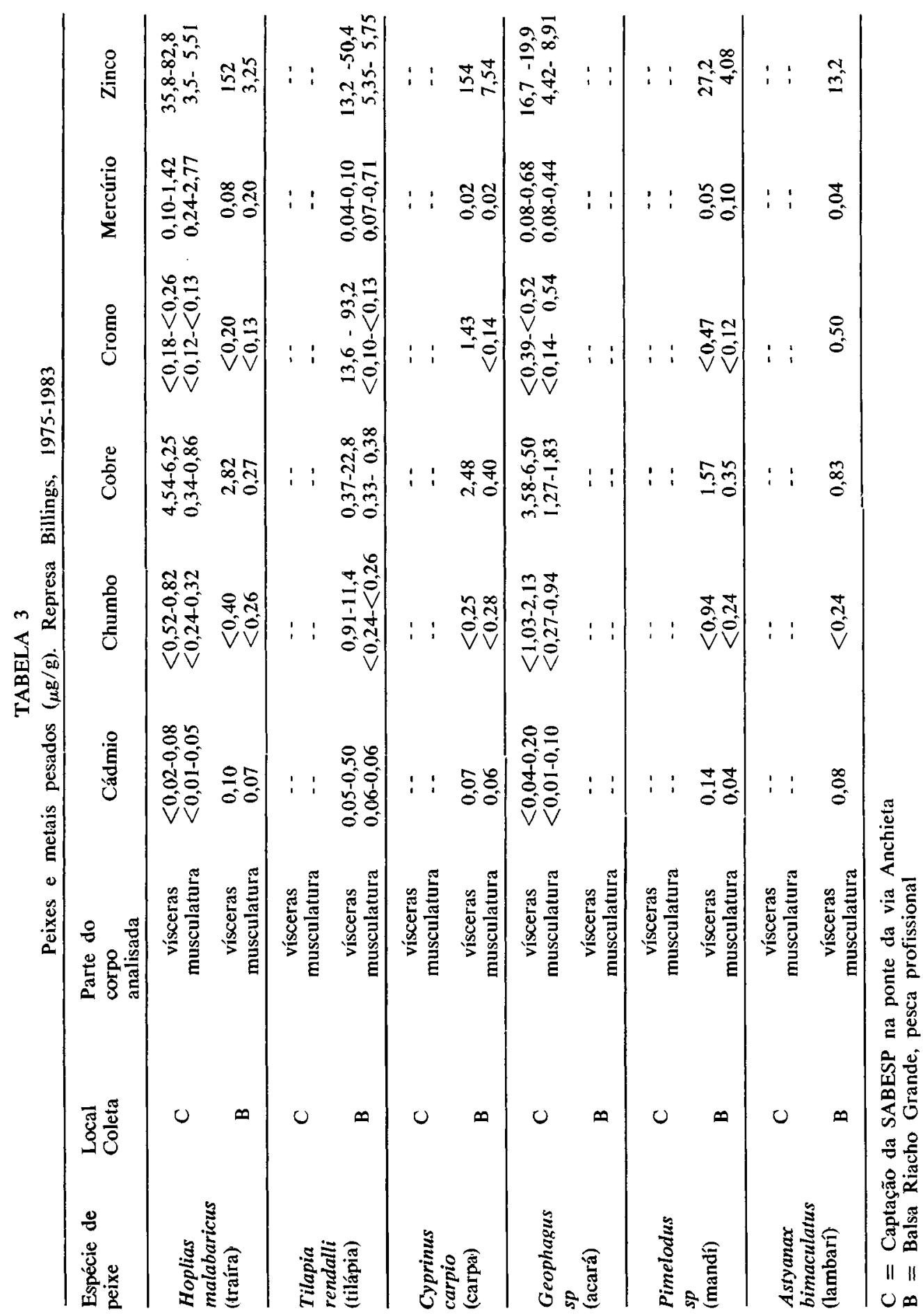


ROCHA, A.A. et al. Produtos de pesca e contaminantes químicos na água da Represa Billings, São Paulo (Brasil). Rev. Saúde públ., S. Paulo, 19:401-10, 1985.

xes, desenvolvimento e manutenção da vida aquática em geral (Tabela 4).

\section{TABELA 4}

Limites máximos permissíveis, na água doce, para sobrevivência de organismos aquáticos.

\begin{tabular}{llll}
\hline Indicador & $\begin{array}{c}\text { Limite } \\
\text { Máximo } \\
(\mathrm{mg} / 1)\end{array}$ & \multicolumn{1}{c}{ Legislação } \\
\hline Cádmio & 0,004 & EPA* $^{*} \quad(1972 ; 1976)$ \\
Chumbo & 0,03 & EPA* $^{*}(1972)$ \\
Cobre & 1,0 & SEMA**(1977) $^{*}$ & \\
Cromo & 0,05 & SEMA**(1977) $^{*}$ & \\
Mercúrio & 0,0002 & EPA* $^{*}(1972)$ \\
Zinco & 5,0 & SEMA**(1977) \\
Níquel & $\begin{array}{c}\text { Não há limite } \\
\text { recomendado }\end{array}$ \\
\hline
\end{tabular}

Fente: Padua e col.15 (1983)

* Environmental Protection Agency (EPA) - EUA

** Secretaria Especial do Meio Ambiente (SEMA) - Brasil

Branco $^{B}$ (1978) discorre sobre experiências realizadas com planárias, apresentando a seguinte ordem decrescente de toxicidade dos metais: prata, mercúrio, cobre, ouro, cádmio, zinco, níquel, cromo, cobalto, alumínio, potássio, chumbo, manganês, magnésio, cálcio, sódio e estrôncio. Essa propriedade parece estar em estreita relação com a capacidade do metal de formar complexos com o protoplasma.

Examinando a Tabela 1 verifica-se que os metais pesados estão próximos aos limites máximos permissíveis à vida aquática (Tabela 4), com exceção do mercúrio, que já está no limite máximo indicado.

Muitas vezes são detectadas baixas concentrações de metais na água, mas tal fato é ilusório, pois, em consequiência das condições anaeróbias, há a formação de sais insolúveis e eliminação por sedimentação. Realmente, em 1973, uma análise de lodo* evidenciava a presença de apreciáveis quantidades de zinco, $0,82 \mathrm{mg} / \mathrm{g}$; chumbo, $0,06 \mathrm{mg} / \mathrm{g}$; mercúrio, $1,2 \mathrm{mg} / \mathrm{g}$ e cromo total, 0,41 $\mathrm{mg} / \mathrm{g}$, o que foi corroborado por análises da CETESB, em 1979.

Em outubro de 1983, foram analisados os peixes provenientes da captação da Companhia de Saneamento Básico do Estado de S. Paulo (SABESP) e da Balsa do Riacho Grande, conforme os dados inseridos na Tabela 3.

A observação dos teores de metais pesados concentrados nas vísceras e na musculatura, que é a parte de maior aproveitamento como alimento, indicou que, para algumas espécies, houve uma superação dos limites máximos estabelecidos pela legislação brasileira e internacional.

A análise dos dados possibilita as seguintes considerações relativas a cada metal pesado, em particular:

\section{a) Cádmio}

Os valores encontrados em quaisquer dos peixes, como a traíra, tilápia, carpa, acará, mandi e lambarí, variaram de $<0,02$ a $0,50 \mu \mathrm{g} / \mathrm{g}$ nas vísceras e de $<0,01$ a $0,10 \mu \mathrm{g} / \mathrm{g}$ na musculatura. Esses teores conservaram-se sempre muito abaixo de $1,0 \mathrm{ppm}$, que é o limite máximo estabelecido para "outros alimentos", na legislação brasileira (Ministério da Saúde ${ }^{14}$, 1977).

Observando a Tabela 4, verifica-se que a legislação americana é bastante restritiva quanto a presença de cádmio na água doce, permitindo um máximo de $0,004 \mu \mathrm{g} / \mathrm{l}$.

\section{b) Chumbo}

A variação foi de $<0,25$ a $11,4 \mu \mathrm{g} / \mathrm{g}$ nas vísceras e de $<0,24$ a $0,94 \mu \mathrm{g} / \mathrm{g}$ na musculatura. Nas vísceras de Tilapia rendalli, proveniente da Balsa do Riacho

\footnotetext{
* Análise realizada pelo autor do presente trabalho (dados inéditos).
} 
ROCHA, A.A. et al. Produtos de pesca e contaminantes químicos na água da Represa Billings. São Paulo (Brasil). Rev. Saúde públ., S. Paulo, 19:401-10, 1985.

Grande, o limite de 0,8 ppm, preconizado pela legislação nacional de 1977 , foi ultrapassado em $3,4 \mu \mathrm{g} / \mathrm{g}$.

O chumbo, ao que se saiba, não possui efeitos benéficos ou nutricionais para os tecidos vivos. $\mathrm{Na}$ realidade, é um metal tóxico que tende a se acumular nos tecidos do homem e de outros animais.

Por essas razões a legislação dos Estados Unidos da América estabelece o limite máximo de $0,03 \mathrm{mg} / \mathrm{l}$ na água doce, como forma de preservar a vida aquática (Padua e col. ${ }^{15}, 1983$ ).

\section{c) Cobre}

O limite máximo estabelecido pela legislação brasileira (Ministério da Saúde $\left.{ }^{14}, 1977\right)$ é de $30 \mathrm{ppm}$ para "outros alimentos", valor que não foi ultrapasdo, tanto nas vísceras (variação de 0,37 a $22,8 \mu \mathrm{g} / \mathrm{g}$ ) como na musculatura $(0,33$ a $1,83 \mu \mathrm{g} / \mathrm{g})$. Visando a preservação da vida aquática, a Secretaria Especial do Meio Ambiente (SEMA), estabelece para o Brasil o limite máximo de $1,0 \mathrm{mg} / \mathrm{l}$ nas águas doces, conforme a indicação da Tabela 4 .

\section{d) Cromo}

A variação no teor de cromo total foi de $<0,18$ a $98,2 \mu \mathrm{g} / \mathrm{g}$ nas vísceras e de $<0,10$ a $0,54 \mu \mathrm{g} / \mathrm{g}$ na musculatura. $\mathrm{O}$ teor mais elevado registrado foi nas vísceras de Tilapia rendalli, que ultrapassou cerca de mil vezes o limite de $0,1 \mu \mathrm{g} / \mathrm{g}$ estabelecido para "outros alimentos", pela legislação nacional.

A atividade biológica do cromo, isto é, seu efeito como metal essencial à vida, está restrita à sua forma trivalente. Não se conhece nenhum efeito produzido por excessivo consumo de cromo. De acordo com a "Environmental Protection Agency ${ }^{11}$ - EPA" (1976), conhece-se mais os problemas relacionados às deficiências de cromo na dieta, levando os animais do teste à hiperglicemia e atraso no crescimento.
O cromo hexavalente, este sim, é corrosivo à mucosa, podendo ser absorvido por ingestão, através da pele ou inalação, provocando câncer de pulmão, perfuração do septo nasal e outras complicações respiratórias.

Essas considerações possibilitam verificar o porque da restrição que a SEMA, através de legislação de 1977 , impõe à presença do cromo nas águas doces, estabelecendo o limite máximo de 0,05 $\mathrm{mg} / \mathrm{l}$, conforme a indicação inserida na Tabela 4 .

\section{e) Mercúrio}

A variação no teor de mercúrio foi de 0,02 a $1,42 \mu \mathrm{g} / \mathrm{g}$ nas vísceras e de 0,02 a $2,77 \mu \mathrm{g} / \mathrm{g}$ na musculatura de $\mathrm{Ho}$ plias malabaricus (traíra), tendo ultrapassado o limite de $0,5 \mu \mathrm{g} / \mathrm{g}$ estabelecido pela legislação nacional para peixes (Ministério da Saúde $\left.{ }^{14}, 1975\right)$. Na musculatura de Tilapia rendalli $(0,71 \mu \mathrm{g} / \mathrm{g})$ e nas vísceras de Geophagus sp (0,68 $\mu \mathrm{g} / \mathrm{g}$ ) foram os valores encontrados.

O mercúrio pode causar intoxicação aguda ou crônica, sendo os efeitos tóxicos variáveis com o estado químico do mesmo e o seu modo de penetração no organismo.

No homem, o envenenamento subagudo ou crônico manifesta-se por: inflamação da boca e gengivas, inchação das glândulas salivares, salivação excessiva, perda dos dentes, tremores musculares, espasmos das extremidades, mudança de personalidade, irritabilidade e nervosismo.

No caso da água e de peixes contaminados, a ingestão do mercúrio orgânico, em doses progressivas, pode promover a deterioração mental, advinda de uma necroencefalopatia tóxica.

Observou-se que a concentração mais baixa de metil-mercúrio no sangue do homem, associada com sintomas tóxicos, é de $0,2 \mu \mathrm{g} / \mathrm{g}$, o que corresponde a uma 
ROCHA, A.A. et al. Produtos de pesca e contaminantes químicos na água da Represa Billings, São Paulo (Brasil). Rev. Saúde públ., S. Paulo, 19:401-10, 1985.

exposição prolongada e contínua de 0,3 $\mathrm{mg} / \mathrm{dia} / 70 \mathrm{~kg}$ de peso (EPA ${ }^{11}, 1976$ ).

Por essas razões, a EPA (Tabela 4) estabelece o limite máximo de 0,0002 $\mathrm{mg} / \mathrm{l}$, na água doce, visando preservar a saúde e a vida aquática em geral.

\section{f) Zinco}

A variação no teor de zinco foi de 13,2 a $15,4 \mu \mathrm{g} / \mathrm{g}$ nas vísceras e de 3,50 a $8,91 \mu \mathrm{g} / \mathrm{g}$ na musculatura. O limite de $50 \mathrm{ppm}$, estabelecido pela legislação nacional para "outros alimentos" (Ministério da Saúde ${ }^{10}$, 1977) foi ultrapassado nas vísceras de traíras. Hoplias malabaricus provenientes da captação da SABESP $(82,8 \mu \mathrm{g} / \mathrm{g})$ e da Balsa do Riacho Grande $(152,0 \mu \mathrm{g} / \mathrm{g})$, nas vísceras de Tilapia rendalli $(50,4 \mu \mathrm{g} / \mathrm{g})$ e de Cyprinus carpio $(154,0 \mu \mathrm{g} / \mathrm{g})$.

O zinco é um elemento essencial e útil ao metabolismo, mas casos de envenenamento podem ocorrer, seja por ingestão de alimentos, por bebidas contaminadas, de poeiras e fumaça com altos teores de zinco ou contato da pele com zinco e seus sais.

Muito embora o envenenamento por zinco através da ingestão de peixes ou moluscos altamente contaminados seja improvável, pois os mesmos, devido à coloração azul-esverdeada produzida, são rejeitados para consumo, há o risco potencial e as doses excessivas desse metal podem causar problemas pulmonares, $\mathrm{fe}-$ bre, calafrios, gastroenterites, sonolência, náusea, desidratação e descoordenação muscular.

Para os peixes, pode afetar a secreção mucosa produzida pelas brânquias $e$, assim, obstruir o espaço interlamelar, bloqueando o movimento respiratório (Rocha ${ }^{17}, 1982$ ).

A SEMA estabelece (Tabela 4), para a água doce, que em território brasileiro o limite seja de $5,0 \mathrm{mg} / 1$, visando preservar a vida aquática.
Verifica-se, pois, que alguns teores dos metais pesados analisados ultrapassam os limites máximos recomendados, tanto nas vísceras como na musculatura dos peixes, principalmente da tilápia, que é o peixe de maior consumo.

Ainda que as vísceras sejam pouco consumidas, porém, em se tratando de peixes de pequeno porte, muitas vezes, pouca evisceração é efetuada pelo pescador e, junto com a musculatura, acabam sendo consumidas grandes parcelas do trato digestivo contaminado.

\section{CONCLUSÕES}

À luz das análises efetuadas, verificase que os peixes da Represa Billings constituem problema de saúde pública por apresentarem contaminação por chumbo, cromo, mercúrio e zinco, tanto nas vísceras como na musculatura, com teores que ultrapassam os níveis máximos permissíveis, estabelecidos pela legislação brasileira e internacional.

Também as concentrações de surfactantes estão em desacordo com a legislação e, além dos problemas estéticos e sanitários, conferem gosto à carne dos peixes.

Em resumo, a pesca comercial está hoje praticamente restrita às cabeceiras dos braços dos rios Capivari e Pequeno, na junção próxima a Ribeirão Pires e nos braços dos rios Curucutu e Taquacetuba. Os: dados da CEAGESP ${ }^{3}$ indicam que, em 1980, apenas 64,0 toneladas de peixes provieram de São Bernardo do Campo.

Nenhum peixe, praticamente, é encontrado junto às balsas de João Basso, Taquacetuba e Bororé e também no "Summit Control". Nem o Poecilidae, Lebistes $s p$, guaru-guaru ou barrigudinho, que passa a vida a deglutir o oxigênio na interface água-ar, junto à superfície de águas estagnadas, é facilmente encontrado. 
ROCHA, A.A. et al. Produtos de pesca e contaminantes químicos na água da Represa Billings. São Paulo (Brasil). Rev. Saúde públ., S. Paulo, 19:401-10, 1985.

A sensível redução da atividade pesqueira, gerando o desemprego, foi e está sendo decorrente da associação dos seguintes fatores, a saber:

a) acentuada poluição doméstica e industrial;

b) redução da atividade de colocação de peixes;

c) intensificação da pesca artesanal e predatória e,

d) superpopulação de tilápias, lambaris, acarás e saguirus, que eliminam e/ou concorrem para atrofiar peixes de outras espécies sobreviventes.
Entretanto, é preciso enfatizar que persiste, ainda, a pesca comercial em pequena escala e a pesca recreativa e, portanto, a qualidade do pescado deve ser preservada, pois a saúde dos consumidores necessita ser salvaguardada. A verificação da qualidade do pescado proveniente da Represa Billings é imperiosa, por existir um grande risco potencial de contaminação. Esse risco de contaminação da fauna íctica fica por conta da eventual presença dos surfactantes, metais pesados e outros poluentes.

ROCHA, A.A. et al. [Fishing yield and chemical contamination of the water of the Billings Reservoir, S. Paulo (Brazil)]. Rev. Saúde públ., S. Paulo, 19:401-10, 1985.

ABSTRACT: Data on detergents and heavy metals such as cadmium, lead, copper, chromium, mercury and zinc are used in order to estimate pollution and sanitary quality of water as well as contamination of fish from Billings Reservoir, SP, Brazil. The results of this work are a warning with regard to the potential risk of human consumption of fish from that Reservoir, even though commercial fishing is now practically restricted to the riverheads of the affluents of the rivers Capivari and Pequeno near Ribeirão Pires and along the rivers Curucutu and Taquacetuba. Data from CEAGESP (Companhia de Entreposto de Armazéns. Gerais do Estado de São Paulo) show that in 1980 only 64 tons of fish came from S. Bernardo do Campo.

UNITERMS: Water pollution, chemical. Fish contamination.

\section{REFERENCIAS BIBLIOGRÁFICAS}

1. ABEL, P.D. Toxicity of synthetic detergents to fish and aquatic invertebrates. J. Fish Biol., 6:279-98, 1974.

2. AMERICAN WATER WORKS ASSOCIATION. Standard methods for the examination of water and wastewater. 15 th ed. Washington, D.C., Joint Editorial Board, 1980.

3. BOLETIM ANUAL: 1980. (Companhia de Entreposto e Armazéns Gerais de São Paulo). São Paulo, 1980.

4. BONETTO, A.A. Problemas relativos a la producción pesquera en los lagos de represas. Comun. cient. CECOAL, Corrientes, Arg., 9:1-21, 1980.

5. BRANCO, S.M. Poluição e intoxicação de peixes. In: Poluição e piscicultura. São Paulo, Comissão Interestadual da Bacia Paraná-Uruguai, 1972. p. 45-52.
6. BRANCO, S.M. Hidrobiologia aplicada a engenharia sanitária. 2. ${ }^{\mathrm{a}}$ ed. São Paulo, CETESB, 1978.

7. CASTRO, N. et al. O problema das espumas formadas no Rio Tietê e na Represa Billings em São Paulo: presença de alquilbenzenosulfonatos, íns metálicos e microrganismos. In: Congresso Brasileiro de Engenharia Sanitária e Ambiental, 10.\%, Manaus, 1979. São Paulo, CETESB, 1979, p. 1-9.

8. CHARLIER, F. Piscifauna uma obra em marcha. São Paulo, Secretaria da Agricultura. Departiamento de Produção Animal. Divisão de Proteção e Produção de Peixes e Animais Silvestres, 1955. (Publ. 3). 
ROCHA, A.A. et al. Produtos de pesca e contaminantes químicos na água da Represa Billings, São Paulo (Brasil). Rev. Saúde públ., S. Paulo, 19:401-10, 1985.

9. CHARLIER, F. Proteção à fauna aquática nos rios brasileiros. 2. ${ }^{\mathrm{a}}$ ed. São Pau10, Secretaria da Agricultura. Departamento de Produção Animal. Divisão de Proteção e Produção de Peixes e Animais Silvestres, 1957. (Publ. 5).

10. DECRETO N. ${ }^{\circ} 55.871$, de 26 de março de 1965. In: Ministério da Saúde. Legislação federal do setor da saúde. $2 .^{\mathrm{a}}$ ed. Brasília, Consultoria Jurídica, 1977. v. 2, p. $498-545$.

11. ENVIRONMENTAL PROTECTION AGENCY. Quality criteria for water. Washington, D.C., Pre-Publication Coppy, 1976.

12. MACHADO, C.M.M. et al. $A$ pesca no Rio Tietê. São Paulo, Secretaria da Agricultura. Departamento de Produção Animal. Divisão de Proteção e Produção de Peixes e Animais Silvestres, 1968. (Publ. 8).

13. MENDES-SOBRINHO, O.T. $O$ barramento dos rios e a fauna ictiológica. São Paulo, CNEC, 1969.
14. MINISTERIO DA SAÚDE. Secretaria Nacional de Saúde. Comissão Nacional de Normas e Padrões para Alimentos. Resolução n. $18 / 75$. Diário Oficial da União, Brasília, 9 dez. 1975.

15. PĀDUA, H.B. et al. Qualidade das águas do Estado de São Paulo para o desenvolvimento e preservação de peixes. In: Congresso Brasileiro de Engenharia Sanitária e Ambiental, 12. Camboriú, SC, 1983. S. Paulo, CETESB, 1983. p. 1-37. (DPES - 10).

16. PAFUNDI, H. Na Billings, a pesca está em extinção. O Estado de S. Paulo, S. Paulo, 30 maio 1976. p. 39.

17. ROCHA, A.A. Efeitos dos poluentes encontrados nos afluentes de uma galvanoplastia. Rev. D.A.E., S. Paulo, 42 (130):89-93, 1982.

18. TURING, H.D. Pollution. London, British Field Sport Society, 1947. v. 2.

Recebido para publicação em 02/01/1985

Reapresentado em 14/06/1985

A provado para publicação em 12/07/1985 